\title{
Titanium Carbide Nanocrystals Synthesized from a Metatitanic Acid-Sucrose Precursor via a Carbothermal Reduction
}

\author{
Hyunho Shin and Jun-Ho Eun \\ Department of Materials Engineering, Gangneung-Wonju National University, 7 Jugheon-gil, Gangneung, \\ Gangwon-do 210-702, Republic of Korea \\ Correspondence should be addressed to Hyunho Shin; hshin@gwnu.ac.kr
}

Received 11 March 2015; Accepted 21 April 2015

Academic Editor: Vesna Mišković-Stanković

Copyright (C) 2015 H. Shin and J.-H. Eun. This is an open access article distributed under the Creative Commons Attribution License, which permits unrestricted use, distribution, and reproduction in any medium, provided the original work is properly cited.

\begin{abstract}
A TiC powder is synthesized from a micron-sized mesoporous metatitanic acid-sucrose precursor (precursor $\mathrm{M}$ ) by a carbothermal reduction process. Control specimens are also prepared using a nanosized $\mathrm{TiO}_{2}$-sucrose precursor (precursor $\mathrm{T}$ ) with a higher cost. When synthesized at $1500^{\circ} \mathrm{C}$ for $2 \mathrm{~h}$ in flowing Ar, the characteristics of the synthesized TiC from precursor $\mathrm{M}$ are similar to those of the counterpart from precursor $\mathrm{T}$ in terms of the crystal size ( 58.5 versus $57.4 \mathrm{~nm}$ ), oxygen content $(0.22 \mathrm{wt} \%$ versus $0.25 \mathrm{wt} \%)$, and representative sizes of mesopores: approximately 2.5 and 19.7-25.0 $\mathrm{nm}$ in both specimens. The most salient differences of the two specimens are found in the $\mathrm{TiC}$ from precursor $\mathrm{M}$ demonstrating (i) a higher crystallinity based on the distinctive doublet peaks in the high-two-theta XRD regime and (ii) a lower specific surface area $\left(79.4\right.$ versus $\left.94.8 \mathrm{~m}^{2} / \mathrm{g}\right)$ with a smaller specific pore volume $\left(0.1\right.$ versus $\left.0.2 \mathrm{~cm}^{3} / \mathrm{g}\right)$ than the counterpart from precursor $\mathrm{T}$.
\end{abstract}

\section{Introduction}

Titanium carbide ( $\mathrm{TiC}$ ) is a representative material of transition metal carbides. It is a technologically important material primarily for cutting tools, abrasives, and polishing pastes. Because (i) its mechanical properties are similar to those of tungsten carbide (WC) that uses expensive cobalt as the sintering aid and (ii) it is sintered with a cheaper sintering aid (nickel), $\mathrm{TiC}$ is also considered as a partial substitute for WC. TiC has been synthesized via various processing routes including combustion reactions [1-5], sol-gel and solution processes [6-11], gas phase or thermal plasma reactions [12-18], mechanothermal reactions [19, 20], and Mg-thermal reductions [21-23], while commercial production primarily uses a carbothermal reduction process [24-45] due to its low cost. The chemical reaction in the carbothermal reduction process is as follows:

$$
\mathrm{TiO}_{2}(\mathrm{~s})+3 \mathrm{C}(\mathrm{s})=\mathrm{TiC}(\mathrm{s})+2 \mathrm{CO}(\mathrm{g})
$$

The Gibbs free energy change for reaction (1) was calculated at varying temperatures using the thermodynamic data given in [46] and the results are presented in Figure 1. As seen in this figure, the Gibbs free energy change for reaction (1) decreases as the partial pressure of $\mathrm{CO}$ gas $\left(p_{\mathrm{CO}}\right)$ decreases from the standard value ( $1 \mathrm{~atm})$; therefore, synthesis of $\mathrm{TiC}$ via reaction (1) is thermodynamically favorable even at room temperature provided $p_{\mathrm{CO}}$ is sufficiently low. The decrease of $p_{\mathrm{CO}}$ can be achieved suitably via flowing an inert gas such as Ar over reaction sample: it removes the $\mathrm{CO}$ gas molecules from the reaction site. However, even under the flowing inert gas atmosphere, the synthesis of $\mathrm{TiC}$ via reaction (1) is usually conducted at the temperature range of $1700-2300^{\circ} \mathrm{C}$ [24] for $10-24 \mathrm{~h}$ due to the kinetic barrier.

From the perspective of reaction kinetics, intimate contact between $\mathrm{TiO}_{2}$ and carbon is crucial to facilitate reaction (1) at high temperatures. In the conventional mechanical mixing of carbon powder and $\mathrm{TiO}_{2}$ powder, it is difficult to achieve a thoroughly mixed state of the two constituents without agglomeration of the same kind. In this regard, the following studies were conducted. In Koc and Folmer [25], hydrocarbon gas was pyrolyzed, followed by the deposition of the pyrolyzed carbon onto the surfaces of $\mathrm{TiO}_{2}$ (P25) particles. While this method ensured intimate contact between the $\mathrm{TiO}_{2}$ and carbon source, the pyrolysis of the hydrocarbon in a rotating chamber with the $\mathrm{TiO}_{2}$ powder is not simple, and it imposes a nonnegligible cost. Shin et al. [26] 


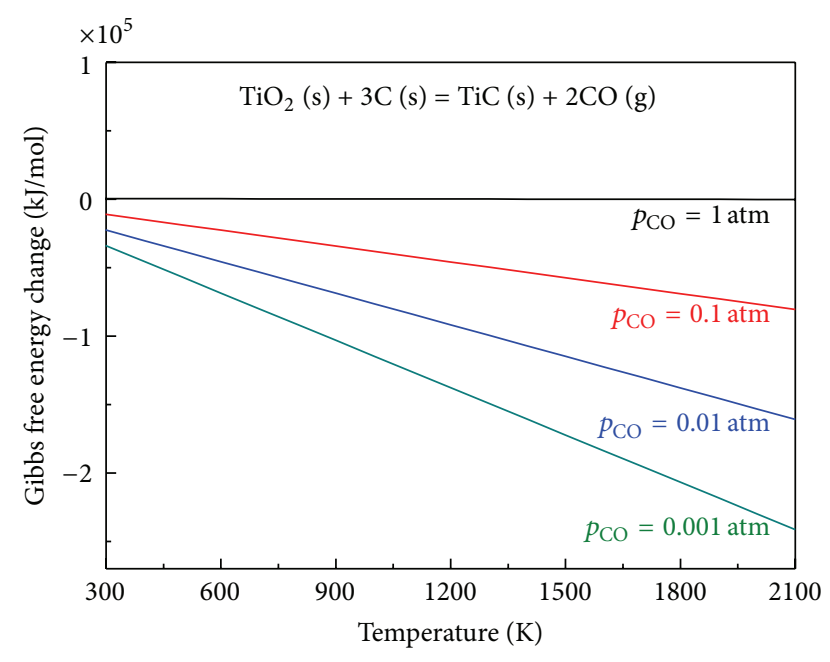

FIGURE 1: Gibbs free energy changes with temperature for reaction (1) at varying partial pressures of CO gas.

and Gotoh et al. [27] utilized cellulose as a carbon source but they used $\mathrm{TiO}_{2}$ sources such as Tyzor- $\mathrm{LA}$ or $\mathrm{TiO}_{2}$ hydrosol. However, these processes also impose a cost burden due to the expensive $\mathrm{TiO}_{2}$ source. In 2009 [28], our research group reported an economical method that ensures intimate contact between the titanium source and carbon source: $\mathrm{TiO}_{2}$ powder ( $\mathrm{P}$-25) was suspended in an aqueous sugar solution (sucrose, $\mathrm{C}_{12} \mathrm{H}_{22} \mathrm{O}_{11}$ ) and dried to form a $\mathrm{TiO}_{2}$ core-sucrose shell precursor. In this precursor, each $\mathrm{TiO}_{2}$ particle was coated with the carbon source (sucrose molecules) without agglomeration of the $\mathrm{TiO}_{2}$ particles. When this precursor was heat-treated at $1600^{\circ} \mathrm{C}$ in flowing $\mathrm{Ar}$, the synthesized TiC exhibited a specific surface area of $137 \mathrm{~m}^{2} / \mathrm{g}$ with an oxygen content of $0.42 \mathrm{wt} \%$.

In this paper, we report an even lower-cost method to carbothermally synthesize $\mathrm{TiC}$ from a micron-sized mesoporous metatitanic acid-sucrose precursor. Metatitanic acid (MTA) is an interim product in the process of producing $\mathrm{TiO}_{2}$ by the sulfuric acid process; the price of MTA should be lower than $\mathrm{TiO}_{2}$. It is a hydrated $\mathrm{TiO}_{2}$ with a mesoporous nature (an average pore size of $3.8 \mathrm{~nm}$ [47]) and a high specific surface area of approximately $337 \mathrm{~m}^{2} / \mathrm{g}$ [47]. Due to its mesoporous nature, water-soluble carbon sources such as sucrose molecules can be suitably impregnated into MTA mesopores in an aqueous solution. This impregnation of sucrose into MTA mesopores is anticipated to ensure intimate contact between the sources of $\mathrm{TiO}_{2}$ and carbon, as well as to reduce the distance of the material transport between the two sources for carbothermal reduction. This study investigates whether there is benefit in using the new MTA-sucrose precursor in synthesizing $\mathrm{TiC}$ by carbothermal reduction compared with using the $\mathrm{TiO}_{2}$-sucrose precursor that was reported in our previous study [28].

\section{Materials and Methods}

A mesoporous MTA (Maanshan Starplanet Chemical Co. Ltd., Maanshan, Anhui, China) with an average particle size
TABLE 1: Specific surface area, specific pore volume, and average pore diameter of the (a) as-received MTA, (b) MTA heat-treated at $600^{\circ} \mathrm{C}$ for $1 \mathrm{~h}$ in air, (c) TiC synthesized from precursor $\mathrm{T}$ at $1500^{\circ} \mathrm{C}$, and (d) $\mathrm{TiC}$ synthesized from precursor $\mathrm{M}$ at $1500^{\circ} \mathrm{C}$.

\begin{tabular}{lcccc}
\hline Samples & (a) & (b) & (c) & (d) \\
\hline $\begin{array}{l}\text { Specific surface area } \\
\left(\text { BET; } \mathrm{m}^{2} / \mathrm{g}\right)\end{array}$ & 377.3 & 79.38 & 94.78 & 79.41 \\
\hline $\begin{array}{l}\text { Average pore diameter } \\
\text { (BJH desorption; } \mathrm{nm})\end{array}$ & 3.88 & 8.43 & $19.7 \& 2.6$ & $25.0 \& 2.6$ \\
\hline $\begin{array}{l}\text { Specific pore volume } \\
\left(\text { BJH desorption; } \mathrm{cm}^{3} / \mathrm{g}\right)\end{array}$ & 0.30 & 0.27 & 0.20 & 0.10 \\
\hline
\end{tabular}

of $1.8 \mu \mathrm{m}$, an average pore diameter of $3.8 \mathrm{~nm}$, and a specific surface area of $377.3 \mathrm{~m}^{2} / \mathrm{g}$ was heat-treated at $600^{\circ} \mathrm{C}$ for $1 \mathrm{~h}$ in air in order to (i) eliminate the overly high amount of water constituent that may inhibit intimate contact between the $\mathrm{TiO}_{2}$ source and the sucrose molecules to be impregnated and (ii) burn out organic matter if any existed. This heat treatment naturally increases the pore sizes (Table 1). The heat-treated MTA was transferred to an aqueous sucrose solution. In this stage, the weight ratio of sucrose to MTA was 3.8 based on separate trials from the perspective of finding the minimum required ratio to produce the single crystalline phase of $\mathrm{TiC}$ without titanium suboxides when synthesized at $1300^{\circ} \mathrm{C}$. Then, the MTA slurry was ultrasonicated for $2 \mathrm{~h}$ in order to impregnate the aqueous sucrose molecules into the pore channels of the heat-treated MTA. Then, the sucroseimpregnated MTA slurry was dried at $110^{\circ} \mathrm{C}$ for $6 \mathrm{~h}$ in an oven, which resulted in a cake form. This sucrose-impregnated MTA is referred to as precursor M. As a control specimen, a sucrose-coated $\mathrm{TiO}_{2}$ (P-25, nanopowder) precursor was prepared following [28], and it is referred to as precursor T. For the subsequent carbothermal reduction process, either precursor $\mathrm{M}$ or $\mathrm{T}$ was transferred into an alumina boat, which was loaded to an alumina tube with a $60 \mathrm{~mm}$ inner diameter. The temperature of the tube furnace was increased to $1250^{\circ} \mathrm{C}-$ $1500^{\circ} \mathrm{C}$ for $2 \mathrm{~h}$ in a flowing argon atmosphere $(1 \mathrm{~L} / \mathrm{min})$. The type B thermocouple was sealed with an alumina protector, which was in contact with the outer surface of the tube.

The MTA powder was characterized by thermogravimetry (TG-DTA; Model STA PT1000, Linseis Messgeräte $\mathrm{GmbH}$, Selb, Germany) at a heating rate of $10^{\circ} \mathrm{C} / \mathrm{min}$ in air. Crystal phases of the reaction products and reactants were identified by X-ray diffraction (XRD) analysis (Model X'PertPro MPD, PANalytical BV, EA Almelo, Netherlands) using $\mathrm{Cu} \mathrm{K} \alpha$ radiation with a scan speed of $0.4^{\circ} / \mathrm{min}$ and a step size of approximately $0.03^{\circ}$. The lattice parameter $a$ was calculated from each diffraction angle $(\theta)$ from the (111), (200), (220), (311), and (222) planes, followed by plotting $a$ as a function of $\cos ^{2} \theta$, based on the relationship for cubic materials [48], as follows:

$$
a=a_{\mathrm{o}}+K \cos ^{2} \theta,
$$

where $a_{\mathrm{o}}$ (the determined lattice parameter of the specimen) is the intercept of the ordinate in the $a$ versus $\cos ^{2} \theta$ plot and $K$ is the slope. The size of the crystals $(D)$ was quantified using 
the degree of broadening of XRD peaks based on the Scherrer equation [48]:

$$
D=\frac{0.94 \lambda}{(\beta \cos \theta)}
$$

where $\beta$ is the full width at half maximum of the diffraction peak (in radian) and $\lambda$ is the wavelength of the X-ray. The $D$ values from all available diffraction peaks were averaged in order to report the crystal size. The oxygen content in the synthesized samples was characterized using an elemental analyzer (Model EA1110, ThermoQuest, Rodano, Italy). The morphology of the powders was observed by scanning electron microscopy (SEM; Model EM-20, COXEM, Daejeon, Korea). The specific surface area was determined by the Brunauer-Emmett-Teller method (BET; Model Macsorb HM-1210, Mountech Co. Ltd., Tokyo, Japan). The pore size distribution was examined by the Barrett-Joyner-Halenda method (BJH; Model ASAP 2010, Micromeritics Instrument Co., Norcross, GA, USA) based on the $\mathrm{N}_{2}$ adsorption and desorption at $77 \mathrm{~K}$. The presence of the mesopores was checked using field emission transmission electron microscopy (FETEM; Model JEM-2100F, JEOL, Tokyo, Japan).

\section{Results and Discussion}

MTA, a hydrated form of $\mathrm{TiO}_{2}$, loses water as the temperature increases as seen in Figure 2. The adsorbed water is removed at $100^{\circ} \mathrm{C}$ (approximately $5 \mathrm{wt} \%$ of the total weight), the weakly bound crystal water at $100-550^{\circ} \mathrm{C}$ (approximately $11 \mathrm{wt} \%$ ), and the strongly bound crystal water at $550-950^{\circ} \mathrm{C}$ (approximately $5 \mathrm{wt} \%$ ). The average pore diameter and specific surface area of the as-received MTA and MTA heat-treated at $600^{\circ} \mathrm{C}$ (for $1 \mathrm{~h}$ in air) are presented in Table 1 . The pore diameter increases with temperature, which naturally decreases the specific surface area. In Table 1, we acknowledge that the value of the specific surface area might be overestimated due to the presence of micropores; the filling of the micropores by $\mathrm{N}_{2}$ molecules is not considered in the BET theory.

The morphologies of the MTA heat-treated for $1 \mathrm{~h}$ in air at 100 and $600^{\circ} \mathrm{C}$ are presented in Figure 3. The $100^{\circ} \mathrm{C}$ heat-treated MTA represents the as-received MTA without adsorbed water. From Figure 3(b), the primary particles of the $600^{\circ} \mathrm{C}$ heat-treated MTA, which was used for the preparation of precursor $\mathrm{M}$, are micron-sized: most primary particles were in the range of $1-3 \mu \mathrm{m}$. The particle size of MTA did not decrease apparently by the heat treatment at $600^{\circ} \mathrm{C}$ compared with the $100^{\circ} \mathrm{C}$ heat-treated MTA (Figure 3(a)). This finding indicates that the elimination of weakly bound crystal water primarily results in increases in the size of the internal pores. As seen in Figure 3(c), P-25 $\mathrm{TiO}_{2}$, which was used to prepare precursor $\mathrm{T}$, is nanosized. The size of its primary particles is known to be approximately $21 \mathrm{~nm}$ [8].

The crystal phases of the as-received MTA, heat-treated MTA at $600^{\circ} \mathrm{C}$, and as-received $\mathrm{TiO}_{2}(\mathrm{P}-25)$ were identified by XRD, and the results are presented in Figure 4 . The crystal form of the as-received MTA and the heat-treated MTA was anatase, while the as-received $\mathrm{TiO}_{2}$ was the mixture of anatase and rutile as well known. Crystal sizes quantified by

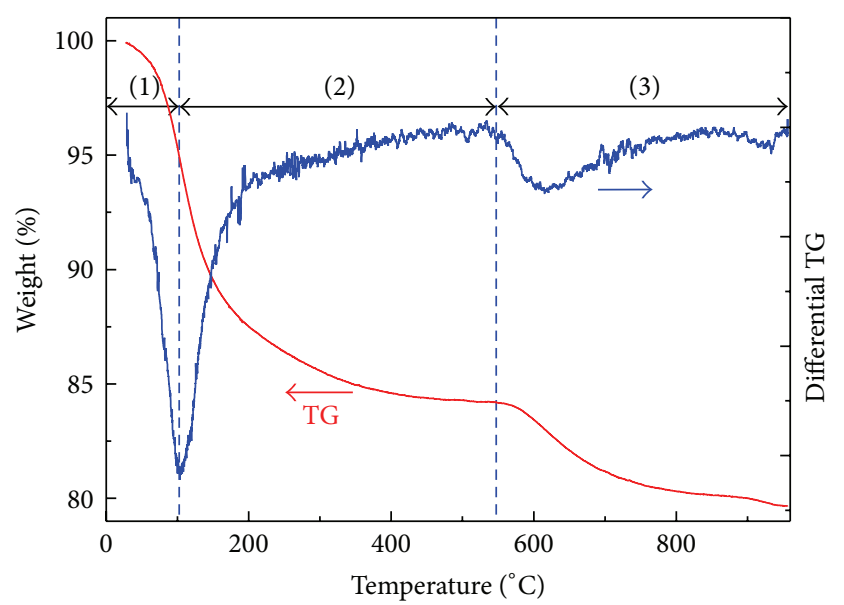

FIgURE 2: Thermogravimetry (TG) and differential TG of MTA. The temperature ranges are marked for the removal of (1) adsorbed water, (2) weakly bound crystal water, and (3) strongly bound crystal water.

the Scherrer equation were 5.8, 16.5, and $21.1 \mathrm{~nm}$, for the asreceived MTA, heat-treated MTA $\left(\right.$ at $\left.600^{\circ} \mathrm{C}\right)$, and as-received P-25 $\mathrm{TiO}_{2}$, respectively. Through combining these results with TG (Figure 2), the MTA is interpreted to be a mixture of anatase nanocrystals and crystal water. In contrast, P-25 $\mathrm{TiO}_{2}$ is water-free, which is well known [49].

The crystal phases of the synthesized product from precursor $\mathrm{M}$ and those from precursor $\mathrm{T}$ were identified by XRD and the results are presented in Figure 5 . As seen in the figure, at a synthesis temperature of $1300^{\circ} \mathrm{C}$ and higher, products from both precursors only exhibited the TiC phase without any titanium suboxides such as $\mathrm{Ti}_{3} \mathrm{O}_{5}$. The diffraction peaks in a high-two-theta regime (for the (110), (210), and (200) planes) are presented in Figure 6. As clearly seen in the figure, the synthesized $\mathrm{TiC}$ from precursor $\mathrm{M}$ exhibited two distinct diffraction peaks for each atomic plane. However, the counterpart from precursor T exhibited a single broad peak for the respective planes. As explained in the Appendix, the peak separation (the observation of two distinct peaks) originally results from two different wavelengths $\left(K \alpha_{1}\right.$ and $\left.K \alpha_{2}\right)$ in the incoming $\mathrm{X}$-ray and is augmented as the diffraction angle increases. In nanocrystals, because peak broadening results from both (i) imperfect crystallinity and (ii) the size effect, the two distinct diffraction peaks are barely observed even at a high diffraction angle, unless its crystallinity is very high. In this regard, crystallinity of $\mathrm{TiC}$ nanocrystals from precursor $\mathrm{M}$ is very high. In this study, the crystal sizes of $\mathrm{TiC}$ from precursors $\mathrm{M}$ and $\mathrm{T}$ are very similar. Therefore, the observed phenomenon of the peak separation in only $\mathrm{TiC}$ from precursor M (Figure 6) means that its crystallinity is certainly higher than that of the counterpart from precursor $\mathrm{T}$. The origin of such higher crystallinity of $\mathrm{TiC}$ from precursor $\mathrm{M}$ may arise from the intimate contact of the reducing agent (residual carbon) with the $\mathrm{TiO}_{2}$ source due to the impregnation of the waterdissolved sucrose molecules into the mesopores of MTA; the distance of the material transport may decrease due to the sucrose impregnation, which facilitates reaction (1). 


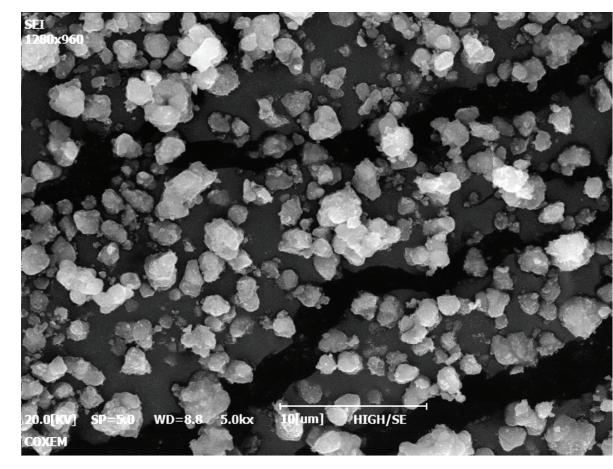

(a)

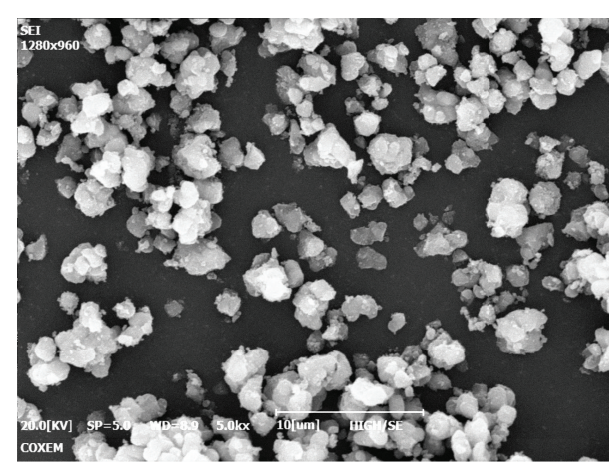

(b)

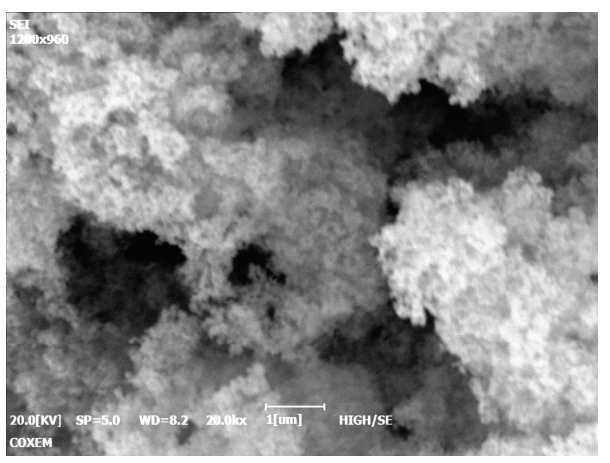

(c)

FIGURE 3: Results of the secondary electron microscopy (SEM) for the MTA powder heat-treated at (a) $100^{\circ} \mathrm{C}$ and (b) $600^{\circ} \mathrm{C}$. (c) The SEM result for the $\mathrm{P}-25 \mathrm{TiO}_{2}$ powder.

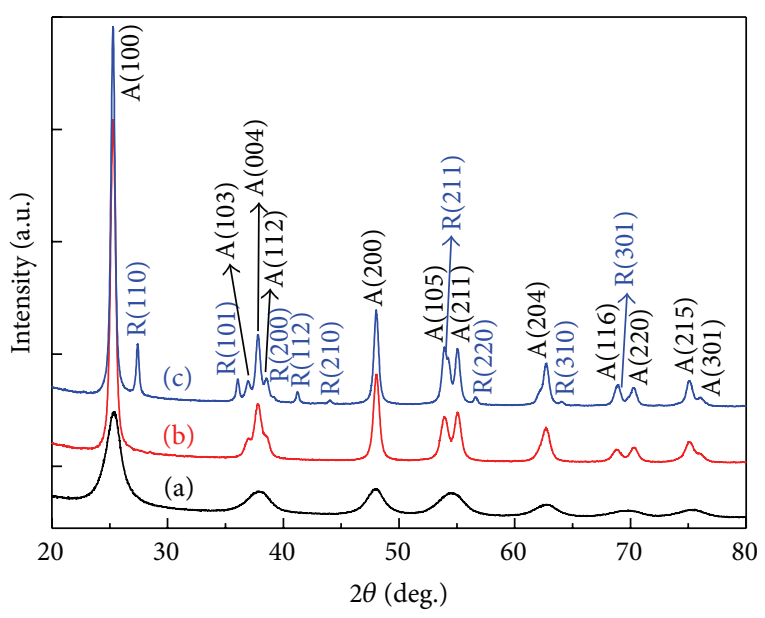

FIGURE 4: X-ray diffraction patterns of the (a) as-received MTA and (b) MTA heat-treated at $600^{\circ} \mathrm{C}$ for $1 \mathrm{~h}$ in air and (c) $\mathrm{P}-25 \mathrm{TiO}_{2}$.

The morphology of the synthesized $\mathrm{TiC}$ powder at $1500^{\circ} \mathrm{C}$ from both precursors is shown in Figure 7. Although it is not easy to quantify the size of the primary particles in the SEM images with micron-scale bars, it is clear that the size of the primary particles of the $\mathrm{TiC}$ from both precursors (Figure 7) was significantly smaller than that of MTA (Figure 3(b)). The crystal size of $\mathrm{TiC}$ was quantified through applying the Scherrer equation [48] to the XRD patterns shown in
Figure 5. The results are presented in Figure 8. The crystal size of the synthesized specimens is in the range of approximately 20-60 nm; it increased with temperature due to the grain growth. The crystal sizes of the synthesized $\mathrm{TiC}$ from both precursors were similar at a given temperature. Furthermore, their trend to increase with temperature increases was similar.

It is known that the nominal $\mathrm{TiC}$ phase that initially forms via carbothermal reduction is not pure $\mathrm{TiC}$ but $\mathrm{TiC}_{x} \mathrm{O}_{y}$, in which the presence of oxygen lowers the lattice parameter [4]. The determined lattice parameters of the synthesized products from both precursors increased with the synthesis temperature (Figure 9(a)), which was accompanied by the decrease of the oxygen content with the synthesis temperature (Figure 9(b)). These observations indicate that the purification process of the $\mathrm{TiC}_{x} \mathrm{O}_{y}$ phase toward pure $\mathrm{TiC}$ progresses as temperature increases. Based on the oxygen content (Figure 9(b)), when synthesized at $1500^{\circ} \mathrm{C}$, the purity of $\mathrm{TiC}$ from precursor $\mathrm{M}$ was higher than that from precursor $\mathrm{T}$ and vice versa at lower temperatures. This result is inconsistent with the trend of the lattice parameter (Figure 9(a)) that exhibited similar lattice parameter values from $1300^{\circ} \mathrm{C}$. However, in this case, greater value is placed on the oxygen content trend (Figure 9(b)), because, in general, there is high data scatter in the determination process of the lattice parameter for each sample from the XRD patterns using (2); for the investigated specimens, the coefficient of determination (the $R^{2}$ value) was in the range of $0.4-0.7$. When synthesized at $1500^{\circ} \mathrm{C}$ for $2 \mathrm{~h}$, the lattice parameter 


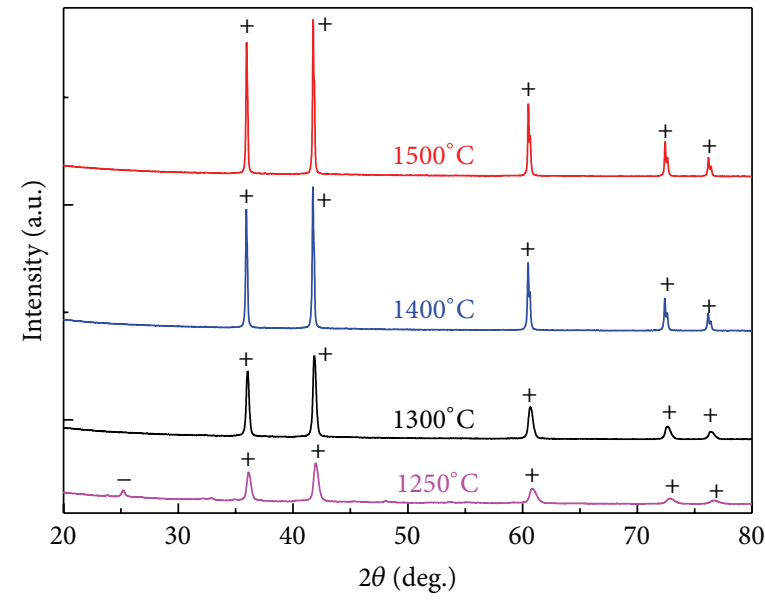

(a)

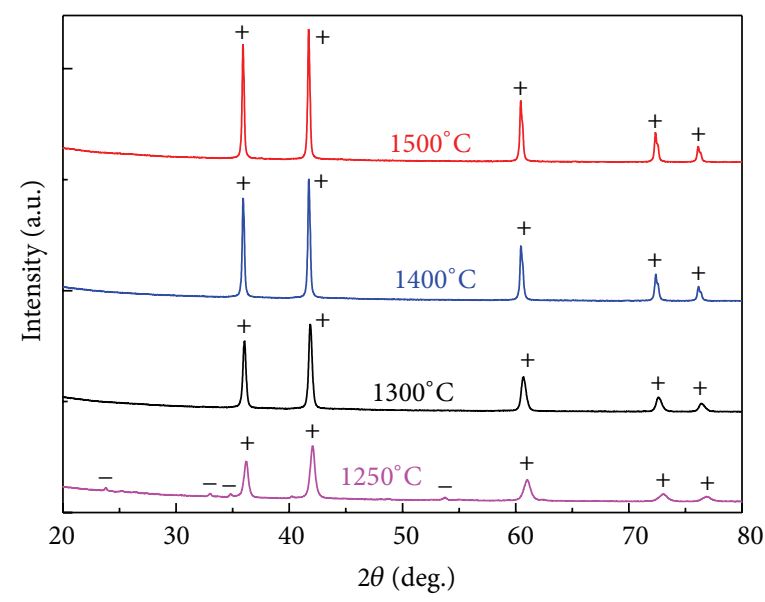

(b)

FIGURE 5: X-ray diffraction (XRD) patterns of the synthesized products from (a) precursor M and (b) precursor T.

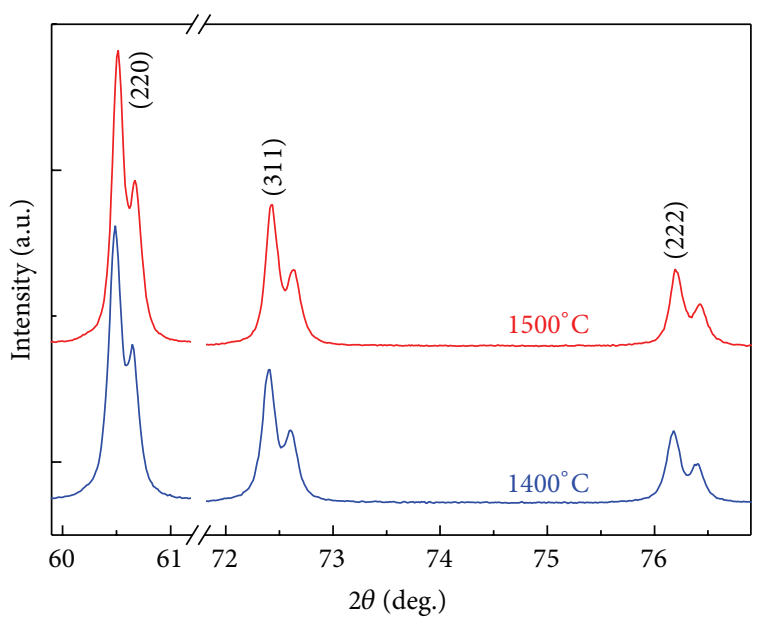

(a)

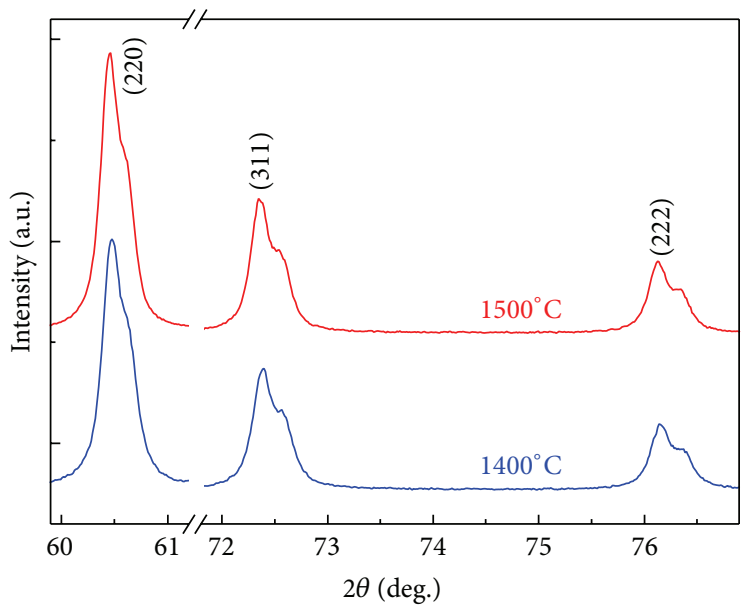

(b)

FIGURE 6: High-two-theta XRD peaks of the synthesized TiC from (a) precursor M and (b) precursor T.

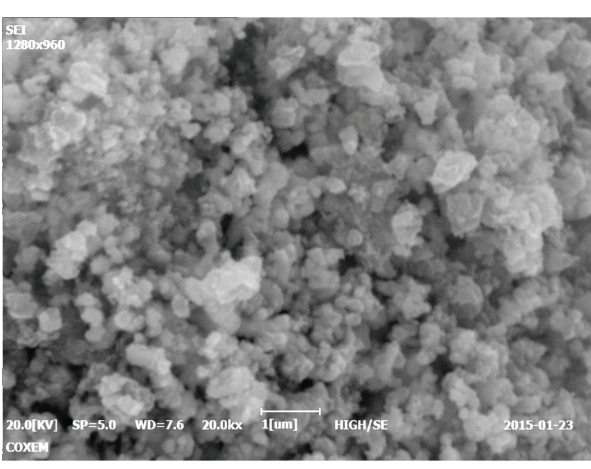

(a)

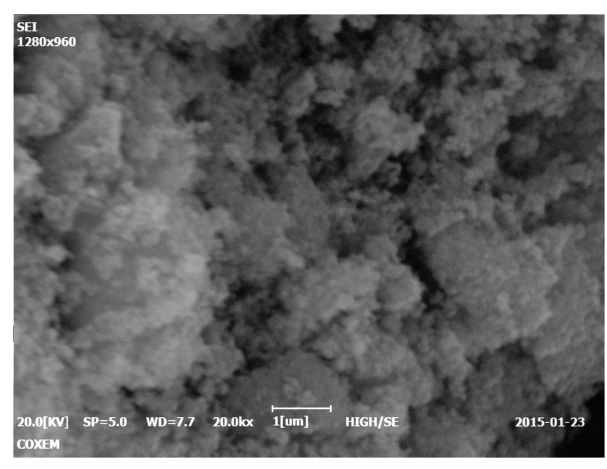

(b)

Figure 7: SEM images of the TiC particles synthesized at $1500^{\circ} \mathrm{C}$ from (a) precursor $\mathrm{M}$ and (b) precursor $\mathrm{T}$. 


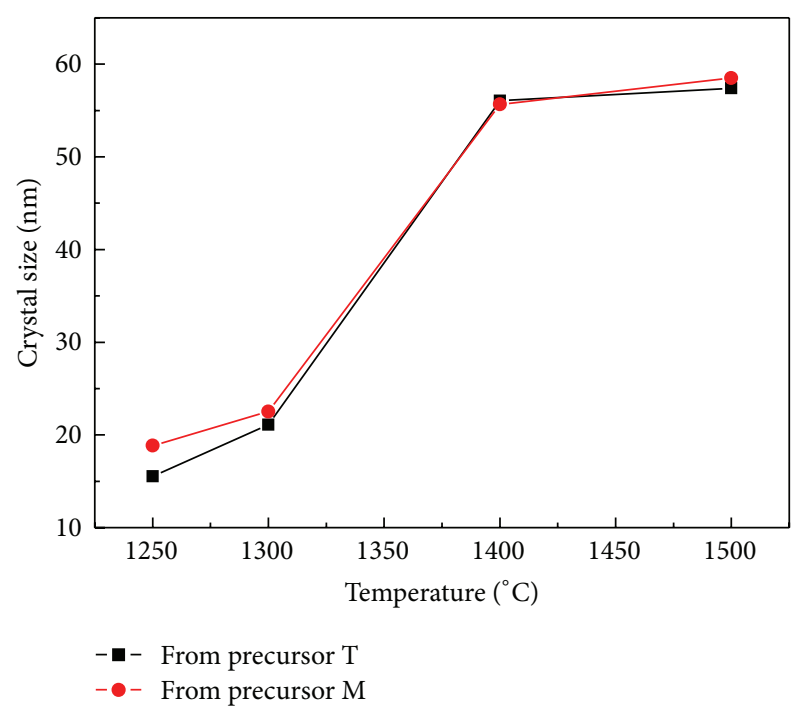

FIgURE 8: Crystal size of the TiC synthesized at varying temperatures from precursors $\mathrm{M}$ and $\mathrm{T}$.

and oxygen content of the TiC synthesized from precursor M were $4.323 \AA$ and $0.22 \mathrm{wt} \%$, respectively, while those from precursor T were $4.323 \AA$ and $0.25 \mathrm{wt} \%$, respectively.

The specific surface area of the synthesized TiC from both precursors is illustrated in Figure 10 as a function of the synthesis temperature. The decreasing trend with the temperature might result from grain growth, particle agglomeration, and possible changes in the pore diameter with temperature (note that there are mesopores in the synthesized TiC, as seen in Figure 11). The TiC from precursor $M$ exhibited a lower specific surface area at the respective temperature than that from precursor $\mathrm{T}$. This observation is consistent with the specific pore volume (in $\mathrm{cm}^{3} / \mathrm{g}$ unit) of the former being significantly smaller than the latter: its value was only half of the latter when synthesized at $1500^{\circ} \mathrm{C}$ (Table 1). When synthesized at $1500^{\circ} \mathrm{C}$, the specific surface areas were 79.41 and $94.78 \mathrm{~m}^{2} / \mathrm{g}$, for the $\mathrm{TiC}$ from precursor $\mathrm{M}$ and precursor $\mathrm{T}$, respectively. As for the reason that $\mathrm{TiC}$ from precursor $\mathrm{M}$ exhibits a lower specific pore volume and a lower specific surface area, this phenomenon may be associated with the sucrose impregnation into the mesopores of MTA, but a further study is needed to clarify this issue.

Figure 11(a) presents the nitrogen adsorption isotherm at $77 \mathrm{~K}$ and the pore volume versus pore diameter relationship for the $\mathrm{TiC}$ synthesized at $1500^{\circ} \mathrm{C}$ from precursor $\mathrm{M}$, based on $\mathrm{BJH}$ analysis. The corresponding data for the counterpart from precursor $\mathrm{T}$ are presented in Figure 12(a). The BJH method for calculating the pore size distributions is based on a model of the adsorbent treated as a collection of cylindrical pores. The theory considers capillary condensation in the pores using the classical Kelvin equation [9], which assumes a hemispherical liquid-vapor meniscus and a well-defined surface tension. The nitrogen adsorption isotherms with pressure (Figures 11(a) and 12(a)) exhibited a type IV isotherm according to the classification of the International Union of Pure and Applied Chemistry (IUPAC), which is typical of mesoporous materials [50]. Furthermore, the pore volume analyses (Figures 11(b) and 12(b)) indicated two representative pore sizes: one with a diameter of approximately 19.7$25.0 \mathrm{~nm}$ and the other with a diameter of approximately $2.5 \mathrm{~nm}$ (Table 1). Regarding the pore size, there is no significant difference between the $\mathrm{TiC}$ from precursor $\mathrm{M}$ and that from precursor T. However, as stated, the specific pore volume of the former $\left(0.1 \mathrm{~cm}^{3} / \mathrm{g}\right)$ was approximately half that of the latter $\left(0.2 \mathrm{~cm}^{3} / \mathrm{g}\right.$; Table 1) when synthesized at $1500^{\circ} \mathrm{C}$. These specific pore volumes indicate open porosity values of 0.02 and 0.04 , respectively, based on a density of $4.93 \mathrm{~g} / \mathrm{cm}^{3}$.

The presence of mesopores in the synthesized $\mathrm{TiC}$ was also verified by FE-TEM. In Figure 13(a), the synthesized $\mathrm{TiC}$ from precursor $\mathrm{M}$ shows a number of distinctive areas marked as P (approximately $3-4 \mathrm{~nm}$ in size). These areas are believed to be mesopores. In the result of the FE-TEM for the $\mathrm{TiC}$ from precursor $\mathrm{T}$ (Figure 13(b)), the images of the mesopore areas were not as distinctive as those in Figure 13(a), but there were many areas with different contrast (marked as P), which are believed to be mesopores. A clearer image of the mesopores in the $\mathrm{TiC}$ specimen from precursor $\mathrm{T}$ is available in [28].

The specific surface area and oxygen content of the TiC from precursor $\mathrm{T}$ in this study were slightly lower than those values in [28]. When synthesized at $1500^{\circ} \mathrm{C}$, these values were $94.8 \mathrm{~m}^{2} / \mathrm{g}$ and $0.25 \mathrm{wt} \%$, respectively, in this study, while they were $147.5 \mathrm{~m}^{2} / \mathrm{g}$ and $0.49 \mathrm{wt} \%$ in [28]. These differences might result from differences in experimental conditions, such as the thermocouple positions, different specimen environment in the furnace due to differences in the shape and size of the sample boat, different sizes in the alumina tube, and different analyses instruments. This study conducted control experiments using precursor $\mathrm{T}$ despite the availability of the data in [28] in order to eliminate these experimental inconsistencies. Therefore, a clear comparison reference ( $\mathrm{TiC}$ from precursor $\mathrm{T}$ ) was prepared in this study for the $\mathrm{TiC}$ samples from precursor $\mathrm{M}$.

\section{Conclusion}

A TiC powder was prepared from a micron-sized mesoporous metatitanic acid-sucrose precursor (precursor M) by the carbothermal reduction process, and it was characterized. Reference specimens were also prepared using a nanosized $\mathrm{TiO}_{2}$-sucrose precursor (precursor $\mathrm{T}$ ) with a higher cost. The $\mathrm{TiC}$ prepared using precursor $\mathrm{M}$ at $1500^{\circ} \mathrm{C}$ for $2 \mathrm{~h}$ in flowing Ar exhibited similar properties to those of the counterpart from precursor $\mathrm{T}$ in terms of the crystal size ( 58.5 versus $57.4 \mathrm{~nm})$, oxygen content $(0.22 \mathrm{wt} \%$ versus $0.25 \mathrm{wt} \%)$, and representative sizes of mesopores: approximately 2.5 and $19.7-$ $25.0 \mathrm{~nm}$ in both specimens. The most salient differences of the two specimens were found in that the TiC from precursor $\mathrm{M}$ demonstrated (i) a higher crystallinity based on the distinctive doublet peaks in the high-two-theta XRD regime and (ii) a lower specific surface area (79.4 versus $\left.94.8 \mathrm{~m}^{2} / \mathrm{g}\right)$ with a smaller specific pore volume $(0.1$ versus $0.2 \mathrm{~cm}^{3} / \mathrm{g}$ ) than that from precursor $\mathrm{T}$. 


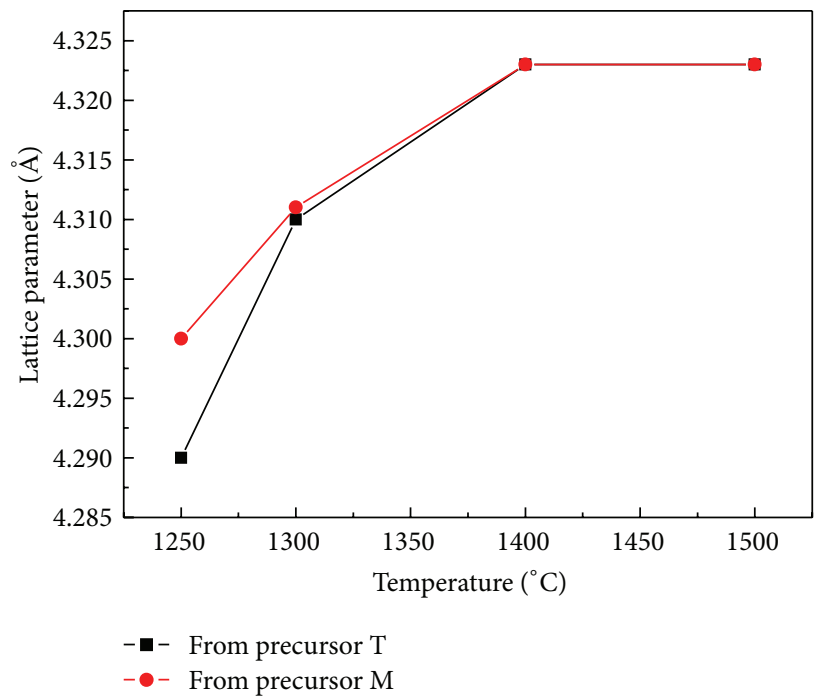

(a)

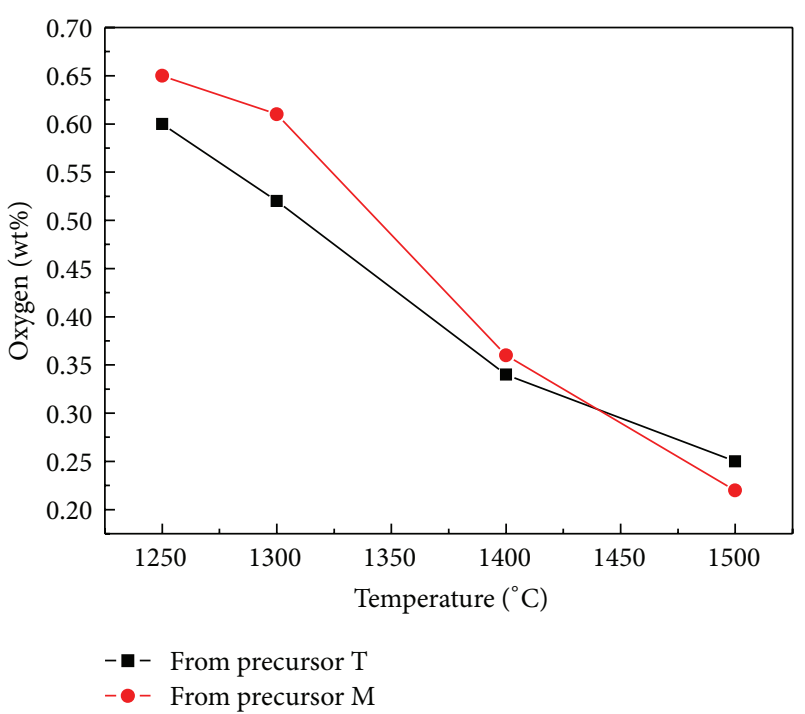

(b)

FIGURE 9: (a) Lattice parameter and (b) oxygen content of TiC synthesized at varying temperatures from precursors $\mathrm{M}$ and $\mathrm{T}$.

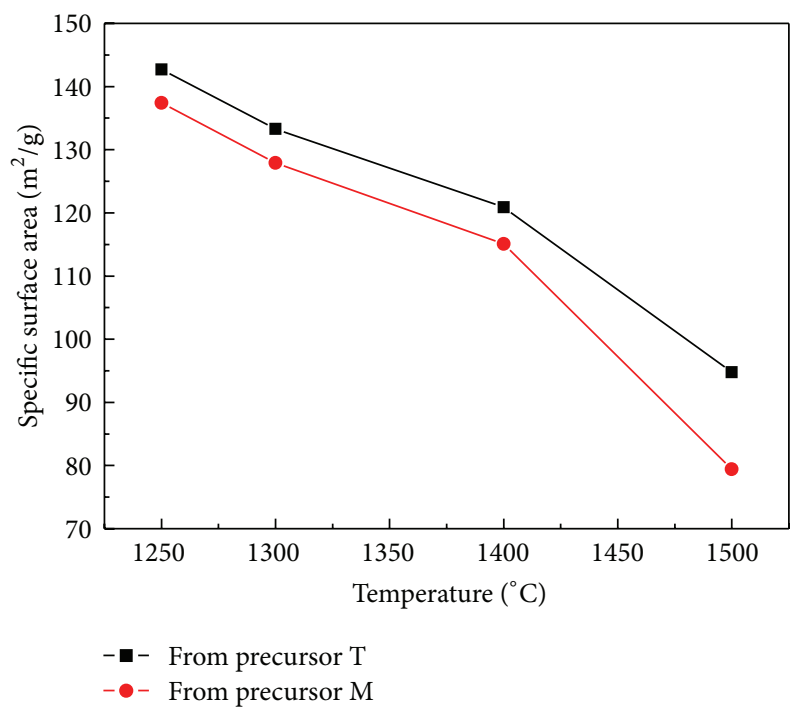

FIGURE 10: Specific surface area of the TiC synthesized at varying temperatures from precursors $\mathrm{M}$ and $\mathrm{T}$.

\section{Appendix}

Consider ideal polycrystals with a perfectly identical atomic spacing $(d)$. The wider peak separation (the observation of two distinct diffraction peaks) at a high-two-theta regime that is observed in these crystals can be understood from (i) Bragg's law and (ii) the sine function characteristics, as follows. Bragg's law is

$$
2 d \sin \theta=\lambda,
$$

where $\lambda$ is the wavelength of the $\mathrm{X}$-ray, $d$ is the spacing of the atomic plane $(h k l)$ diffracting the $\mathrm{X}$-ray, and $2 \theta$ is the diffraction angle. According to this law, the difference of
TABLE 2: Calculated $\Delta \theta$ (peak separation) using (A.2) for varying values of $d$-spacing.

\begin{tabular}{lccc}
\hline$d(\AA)$ & $\begin{array}{c}\theta \text { (deg.) } \\
\text { from (A.1) } \\
(\lambda=1.541874 \AA)\end{array}$ & $\begin{array}{c}\Delta \sin \theta \\
\text { from }(\text { A.2 })\end{array}$ & $\Delta \theta$ (deg.) \\
\hline 9.0 & 4.9140 & $0.003828 \AA)$ & \\
3.0 & 14.8909 & 0.0002 & 0.0122 \\
2.0 & 22.6728 & 0.0010 & 0.0366 \\
1.5 & 30.9278 & 0.0013 & 0.0548 \\
1.0 & 50.4384 & 0.0019 & 0.0731 \\
\hline
\end{tabular}

wavelengths $(\Delta \lambda)$ between $\mathrm{K} \alpha_{1}(1.540598 \AA$ for $\mathrm{Cu})$ and $\mathrm{K} \alpha \alpha_{2}$ $(1.544426 \AA$ for $\mathrm{Cu})$ results in differences of the value of $\sin \theta$ $(\Delta \sin \theta)$ as follows:

$$
\frac{\Delta \lambda}{2 d}=\Delta \sin \theta .
$$

Because the value of $\Delta \lambda$ is constant $(0.003828 \AA), \Delta \sin \theta$ is constant for a given $d$-spacing. As apparent in the $\sin \theta$ versus $\theta$ relationship (Figure 14), a constant value of $\Delta \sin \theta$ results in a wider separation of $\theta(\Delta \theta)$ in higher $\theta$ regimes. In Figure 14, the terms $\Delta \sin \theta$ and $\Delta \theta$ denote the degree of separation of the two diffraction peaks from $\mathrm{K} \alpha_{1}$ and $\mathrm{K} \alpha_{2}$ rays. According to (2), constant $\Delta \lambda$ results in a higher value of $\Delta \sin \theta$ as $\theta$ increases due to the diminished $d$ value (see Table 2). Then, the $\Delta \theta$ value increases further with $\theta$ due to the characteristics of the sine function. Table 2 presents the calculated $\Delta \theta$ (peak separation) using (A.2) for varying values of $d$-spacing. In this table, $\theta$ was determined by (A.1) based on the weightaveraged $\lambda$ value of $1.541874 \AA$ (a weight factor of 2 was applied for the $\mathrm{K} \alpha_{1}$ wavelength in order to reflect the intensity ratio of the diffraction peak from $\mathrm{K} \alpha_{1}$ to that from $\mathrm{K} \alpha_{2}$ ). As apparent in Table 2, the peak separation $(\Delta \theta)$ originating 


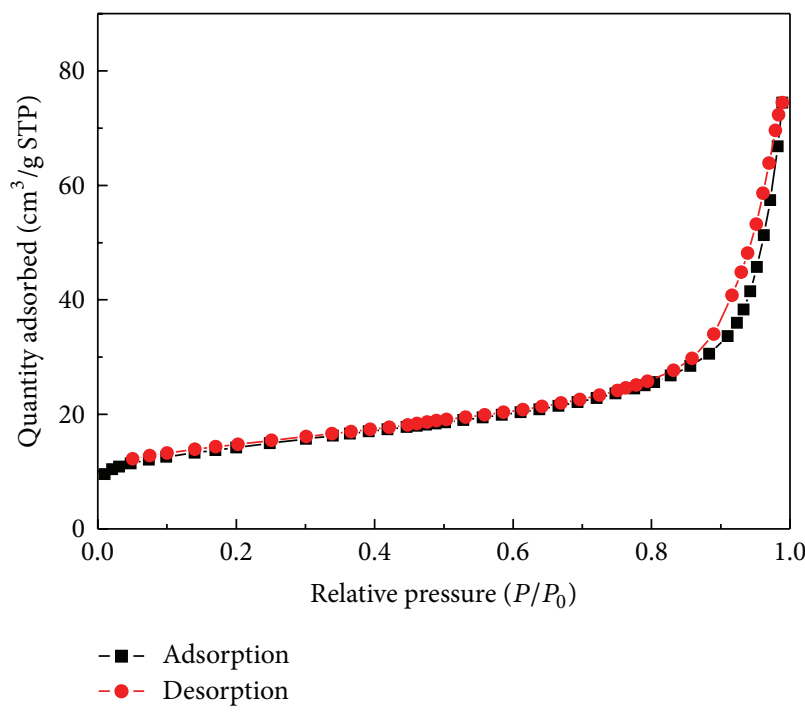

(a)

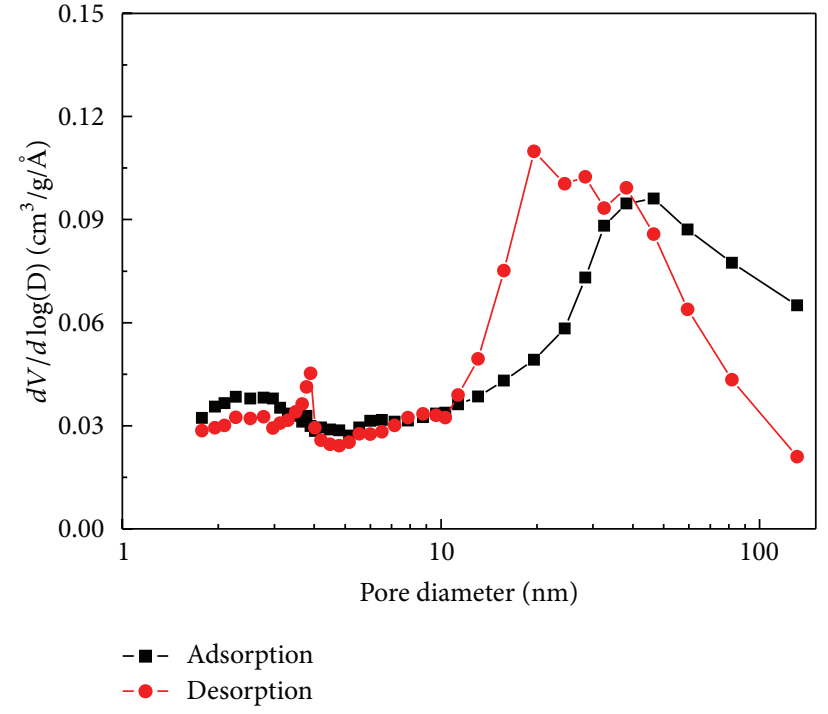

(b)

FIGURE 11: Results of the $\mathrm{BJH}$ analyses for the TiC synthesized from precursor $\mathrm{M}$ at $1500^{\circ} \mathrm{C}$ : (a) the nitrogen adsorption isotherm at $77 \mathrm{~K}$ as a function of the relative pressure and (b) the pore volume versus pore diameter relationship.

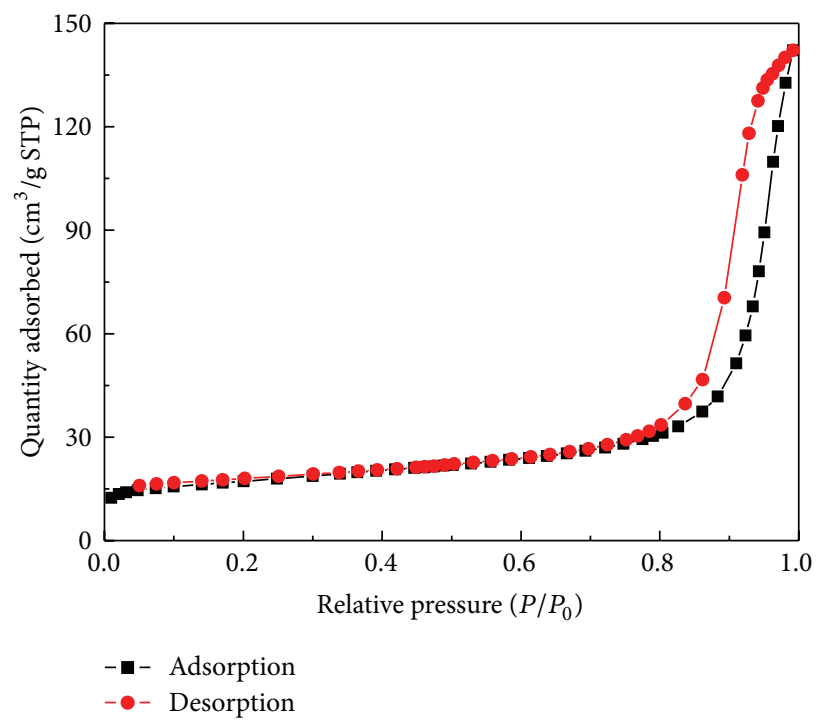

(a)

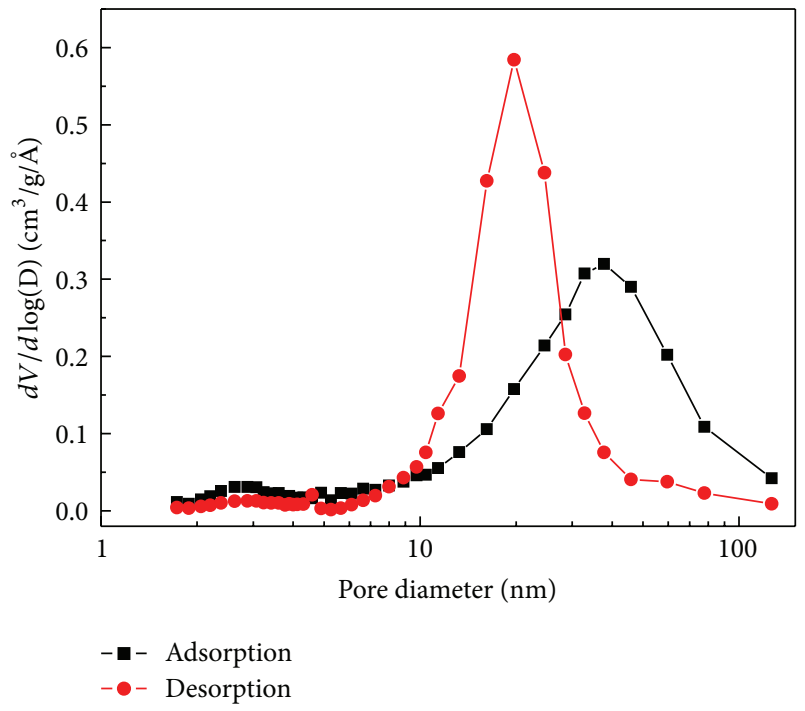

(b)

FIGURE 12: Results of the $\mathrm{BJH}$ analyses for the TiC synthesized from precursor $\mathrm{T}$ at $1500^{\circ} \mathrm{C}$ : (a) the nitrogen adsorption isotherm at $77 \mathrm{~K}$ as a function of the relative pressure and (b) the pore volume versus pore diameter relationship.

from the two different wavelengths ( $\mathrm{K} \alpha$ doublet) widens as the diffraction angle $\theta$ increases.

Consider a real crystal with a range of $d$-spacing values for a given atomic plane due to imperfect crystallinity. Assume that $\lambda$ has a single value (the weight-averaged value of $1.541874 \AA$ ). Then, variations of the $d$-spacing $(\Delta d)$ yield variations of $\Delta \sin \theta(\Delta \theta): 2 \Delta d=\lambda / \Delta \sin \theta$. The terms $\Delta \sin \theta$ and $\Delta \theta$ here now denote the degree of broadening of a given peak when an X-ray with a fixed value of $\lambda$ diffracts. The lower the crystallinity (i.e., a larger $\Delta d$ ), the broader the diffraction peaks (a larger $\Delta \theta$ ). The broadening of a peak due to imperfect crystallinity screens the peak separation phenomenon, which contributes to yielding a single broad peak even at a high diffraction angle as seen in Figure 6(b).

For nanocrystals, there is another source of peak broadening apart from imperfect crystallinity. The small size of the nanocrystals is another source for peak broadening as described in (3). In nanocrystals, the peak separation is barely observed, even at a high diffraction angle, because the two sources of peak broadening described above (i.e., the small size and imperfect crystallinity) are operating simultaneously. Therefore, for a nanocrystal, the peak separation 


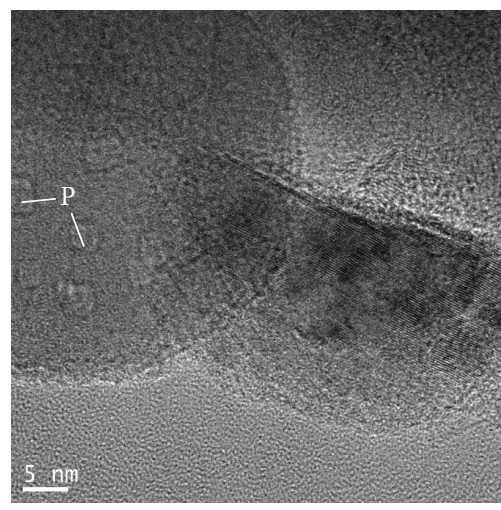

(a)

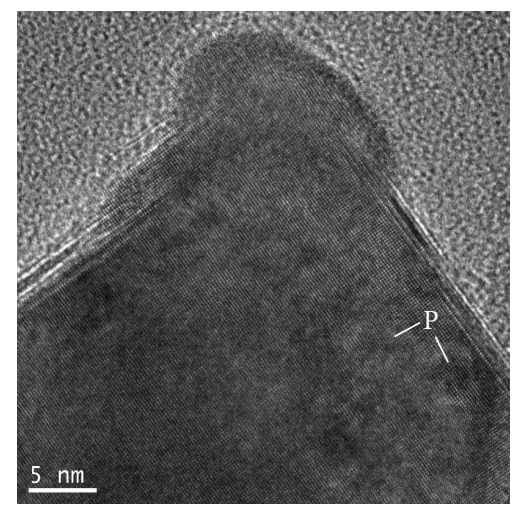

(b)

FIgURE 13: Results of the FE-TEM for the TiC synthesized at $1500^{\circ} \mathrm{C}$ from (a) precursor $\mathrm{M}$ and (b) precursor $\mathrm{T}$.

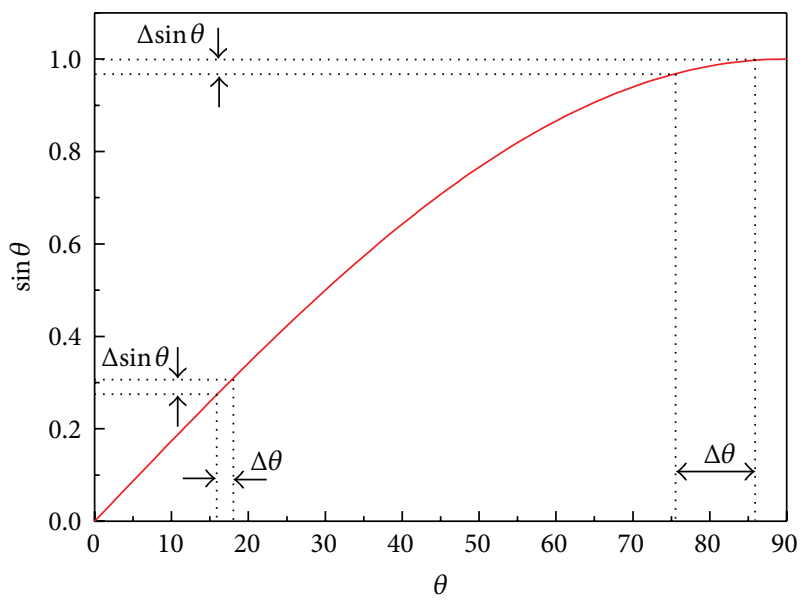

FIGURE 14: Sine function illustrating that a given variation of $\Delta \sin \theta$ results in a larger peak separation $(\Delta \theta)$ at a high diffraction angle $(\theta)$.

is only observed when its crystallinity is very high. In this regard, TiC nanocrystals that are synthesized from precursor M (Figure 6(a)) possess a very high crystallinity, which is significantly higher than that from precursor $\mathrm{T}$.

\section{Conflict of Interests}

The authors declare that there is no conflict of interests regarding the publication of this paper.

\section{Acknowledgment}

This study was financially supported by the Ministry of Education, Science, and Technology through the National Research Foundation (NRF) of Korea under Contract no. 2013R1A1A2007455.

\section{References}

[1] H. H. Nersisyan, J. H. Lee, and C. W. Won, "Self-propagating high-temperature synthesis of nano-sized titanium carbide powder," Journal of Materials Research, vol. 17, no. 11, pp. 28592864, 2002.

[2] M. E. Mullins and E. Riley, "The effect of carbon morphology on the combustion synthesis of titanium carbide," Journal of Materials Research, vol. 4, no. 2, pp. 408-411, 1989.

[3] Z. A. Munir, "Synthesis of high temperature materials by selfpropagating combustion methods," American Ceramic Society Bulletin, vol. 67, no. 2, pp. 342-349, 1988.

[4] P. Persson, A. E. W. Jarfors, and S. Savage, "Self-propagating high-temperature synthesis and liquid-phase sintering of $\mathrm{TiC} / \mathrm{Fe}$ composites," Journal of Materials Processing Technology, vol. 127, no. 2, pp. 131-139, 2002.

[5] S. Niyomwas, "Synthesis of titanium carbide from wood by self-propagating high temperature synthesis," Songklanakarin Journal of Science and Technology, vol. 32, no. 2, pp. 175-179, 2010.

[6] F. Hosseinzadeh, H. Sarpoolaki, and H. Hashemi, "Precursor selection for sol-gel synthesis of titanium carbide nanopowders by a new intuitionistic fuzzy multi-attribute group decisionmaking model," International Journal of Applied Ceramic Technology, vol. 11, no. 4, pp. 681-698, 2014.

[7] A. Biedunkiewicz, P. Figiel, M. Krawczyk, and U. GabrielPolrolniczak, "Simultaneous synthesis of molybdenum carbides and titanium carbides by sol-gel method," Journal of Thermal Analysis and Calorimetry, vol. 113, no. 1, pp. 253-258, 2013.

[8] D. W. Flaherty, R. A. May, S. P. Berglund, K. J. Stevenson, and C. B. Mullins, "Low temperature synthesis and characterization of nanocrystalline titanium carbide with tunable porous architectures," Chemistry of Materials, vol. 22, no. 2, pp. 319-329, 2010.

[9] Z. Jiang and W. E. Rhine, "Preparation of TiN and TiC from a polymeric precursor," Chemistry of Materials, vol. 3, no. 6, pp. 1132-1137, 1991.

[10] S. Dutremez, P. Gerbier, C. Guérin, B. Henner, and P. Merle, "Metal alkoxide/hexa-2,4-diyne-1,6-diol hybrid polymers: synthesis and use as precursors to metal carbides and nitrides," Advanced Materials, vol. 10, no. 6, pp. 465-470, 1998. 
[11] H. Preiss, L.-M. Berger, and D. Schultze, "Studies on the carbothermal preparation of titanium carbide from different gel precursors," Journal of the European Ceramic Society, vol. 19, no. 2, pp. 195-206, 1999.

[12] D. E. Grove, U. Gupta, and A. W. Castleman Jr., "Effect of carbon concentration on changing the morphology of titanium carbide nanoparticles from cubic to cuboctahedron," ACS Nano, vol. 4, no. 1, pp. 49-54, 2010.

[13] S. R. Qi, X. T. Huang, Z. W. Gan, X. X. Ding, and Y. Cheng, "Synthesis of titanium carbide nanowires," Journal of Crystal Growth, vol. 219, no. 4, pp. 485-488, 2000.

[14] R. Alexandrescu, E. Borsella, S. Botti et al., "Synthesis of TiC and $\mathrm{SiC} / \mathrm{TiC}$ nanocrystalline powders by gas-phase laser-induced reaction," Journal of Materials Science, vol. 32, no. 21, pp. 56295635, 1997.

[15] M. S. Noel and D. Kovar, "Laser chemical vapor deposition of TiC on tantalum," Journal of Materials Science, vol. 37, no. 4, pp. 689-697, 2002.

[16] D. W. Flaherty, N. T. Hahn, D. Ferrer, T. R. Engstrom, P. L. Tanaka, and C. B. Mullins, "Growth and characterization of high surface area titanium carbide," The Journal of Physical Chemistry C, vol. 113, no. 29, pp. 12742-12752, 2009.

[17] L. Tong and R. G. Reddy, "Synthesis of titanium carbide nanopowders by thermal plasma," Scripta Materialia, vol. 52, no. 12, pp. 1253-1258, 2005.

[18] X.-L. Jiang and M. Boulos, "Synthesis of titanium carbide by induction plasma reactive spray," Transactions of Nonferrous Metals Society of China, vol. 14, no. 1, pp. 15-19, 2004.

[19] M. Razavi, S. Zamani, M. R. Rahimipour, and P. Khatibzadeh, "Pyromilling synthesis of nanocrystalline titanium carbide," Nano, vol. 8, no. 2, Article ID 1350023, 2013.

[20] B. Li, L. Cui, Y. Zheng, and C. Xu, "Synthesis of TiC powder by mechanical alloying of titanium and asphalt," Chinese Journal of Chemical Engineering, vol. 15, no. 1, pp. 138-140, 2007.

[21] Y. Chen, Y. Deng, H. Zhang, L. Wang, and J. Ma, "A novel and simple route to synthesis nanocrystalline titanium carbide via the reaction of titanium dioxide and different carbon source," Materials Sciences and Applications, vol. 02, no. 11, pp. 16221626, 2011.

[22] D. W. Lee and B. K. Kim, "Synthesis of nano-structured titanium carbide by Mg-thermal reduction," Scripta Materialia, vol. 48, no. 11, pp. 1513-1518, 2003.

[23] D. W. Lee, S. Alexandrovskii, and B. K. Kim, "Mg-thermal reduction of $\mathrm{TiCl}_{4}+\mathrm{C}_{x} \mathrm{Cl}_{4}$ solution for producing ultrafine titanium carbide," Materials Chemistry and Physics, vol. 88, no. 1, pp. 23-26, 2004.

[24] N. A. Hassine, J. G. P. Binner, and T. E. Cross, "Synthesis of refractory metal carbide powders via microwave carbothermal reduction," International Journal of Refractory Metals and Hard Materials, vol. 13, no. 6, pp. 353-358, 1995.

[25] R. Koc and J. S. Folmer, "Carbothermal synthesis of titanium carbide using ultrafine titania powders," Journal of Materials Science, vol. 32, no. 12, pp. 3101-3111, 1997.

[26] Y. Shin, X. S. Li, C. Wang, J. R. Coleman, and G. J. Exarhos, "Synthesis of hierarchical titanium carbide from titania-coated cellulose paper," Advanced Materials, vol. 16, no. 14, pp. 12121215, 2004.

[27] Y. Gotoh, K. Fujimura, M. Koike et al., "Synthesis of titanium carbide from a composite of $\mathrm{TiO}_{2}$ nanoparticles/methyl cellulose by carbothermal reduction," Materials Research Bulletin, vol. 36, no. 13-14, pp. 2263-2275, 2001.
[28] S.-T. Bae, H. Shin, H. S. Jung, and K. S. Hong, "Synthesis of titanium carbide nanoparticles with a high specific surface area from $\mathrm{a} \mathrm{TiO}_{2}$ core-sucrose shell precursor," Journal of the American Ceramic Society, vol. 92, no. 11, pp. 2512-2516, 2009.

[29] L. M. Berger, "Titanium carbide synthesis from titanium dioxide and carbon black," International Journal of Refractory Metals and Hard Materials, vol. 3, no. 1, pp. 3-15, 1992.

[30] A. Maitre, D. Tetard, and P. Lefort, "Role of some technological parameters during carburizing titanium dioxide," Journal of the European Ceramic Society, vol. 20, no. 1, pp. 15-22, 2000.

[31] Y.-C. Woo, H.-J. Kang, and D. J. Kim, "Formation of TiC particle during carbothermal reduction of $\mathrm{TiO}_{2}$," Journal of the European Ceramic Society, vol. 27, no. 2-3, pp. 719-722, 2007.

[32] H. Preiss, L.-M. Berger, and D. Schultze, "Studies on carbothermal preparation of titanium carbide from different gel precursors," Journal of the European Ceramic Society, vol. 19, no. 2, pp. 195-206, 1999.

[33] C. Navin, S. Meenakshi, S. D. Kumar, and S. S. Amritphale, "Synthesis of nano-TiC powder using titanium gel precursor and carbon particles," Materials Letters, vol. 63, no. 12, pp. 10511053, 2009.

[34] W. Sen, B.-Q. Xu, B. Yang et al., "Preparation of TiC powders by carbothermal reduction method in vacuum," Transactions of Nonferrous Metals Society of China, vol. 21, no. 1, pp. 185-190, 2011.

[35] D. V. Bavbande, R. Mishra, and J. M. Juneja, "Studies on the kinetics of synthesis of $\mathrm{TiC}$ by calciothermic reduction of $\mathrm{TiO}_{2}$ in presence of carbon," Journal of Thermal Analysis and Calorimetry, vol. 78, no. 3, pp. 775-780, 2004.

[36] V. D. Lyubimov, S. I. Alyamovskii, and G. P. Shveikin, "Mechanism of the reduction of titanium oxides by carbon," Russian Journal of Inorganic Chemistry, vol. 26, no. 9, pp. 1243-1247, 1981.

[37] M. Razavi, M. R. Rahimipour, and R. Kaboli, "Synthesis of $\mathrm{TiC}$ nanocomposite powder from impure $\mathrm{TiO}_{2}$ and carbon black by mechanically activated sintering," Journal of Alloys and Compounds, vol. 460, no. 1-2, pp. 694-698, 2008.

[38] B. H. Lohse, A. Calka, and D. Wexler, "Effect of starting composition on the synthesis of nanocrystalline TiC during milling of titanium and carbon," Journal of Alloys and Compounds, vol. 394, no. 1-2, pp. 148-151, 2005.

[39] X. Cui, L. Cui, L. Wang, and M. Qi, "Synthesis of titanium carbide powder from $\mathrm{TiO}_{2}$ and petroleum coke by reactive milling," Petroleum Science and Technology, vol. 20, no. 9-10, pp. 999-1007, 2002.

[40] X. Feng, Y. Bai, B. Lu et al., "Easy synthesis of TiC nanocrystallite," Journal of Crystal Growth, vol. 264, no. 1-3, pp. 316-319, 2004.

[41] D. Sarkar, M. Chu, S.-J. Cho, Y. I. Kim, and B. Basu, "Synthesis and morphological analysis of titanium carbide nanopowder," Journal of the American Ceramic Society, vol. 92, no. 12, pp. 2877-2882, 2009.

[42] L. Zhang, J. N. Hu, A. A. Voevodin, and H. Fong, "Synthesis of continuous $\mathrm{TiC}$ nanofibers and/or nanoribbons through electrospinning followed by carbothermal reduction," Nanoscale, vol. 2, no. 9, pp. 1670-1673, 2010.

[43] B. Shahbahrami, M. Hakami, H. Bastami, E. Nadi-Mobarakeh, and M. Malekmohammadi, "Synthesis of titanium carbide powder by carbothermic reduction method," Materials Research Innovations, vol. 14, no. 1, pp. 87-88, 2010.

[44] P. Liu, Q. Yang, A. Shui et al., "Microwave synthesis of nanotitanium carbide," Advanced Materials Research, vol. 399-401, pp. 561-564, 2011. 
[45] K. Huo, Y. Hu, Y. Ma, Y. Lü, Z. Hu, and Y. Chen, "Synthesis and field emission properties of titanium carbide nanowires," Nanotechnology, vol. 18, no. 14, Article ID 145615, 2007.

[46] I. Barin, Thermochemical Data of Pure Substances, VCH VerlagsgesellschaftmbH, Wiley, 3rd edition, 1995.

[47] S.-K. Park and H. Shin, "Microstructural evolution of metatitanic acid with temperature and its photosensitization property," Reaction Kinetics, Mechanisms and Catalysis, vol. 110, no. 1, pp. 237-249, 2013.

[48] B. D. Cullity, Elements of X-Ray Diffraction, Addison-Wesley, London, UK, 2nd edition, 1978.

[49] Sigma-Aldrich, "Product specification, titanium(IV) oxide," Product number 718467.

[50] S. J. Gregg and K. S. W. Sing, Adsorption, Surface Area and Porosity, Academic Press, New York, NY, USA, 1967. 

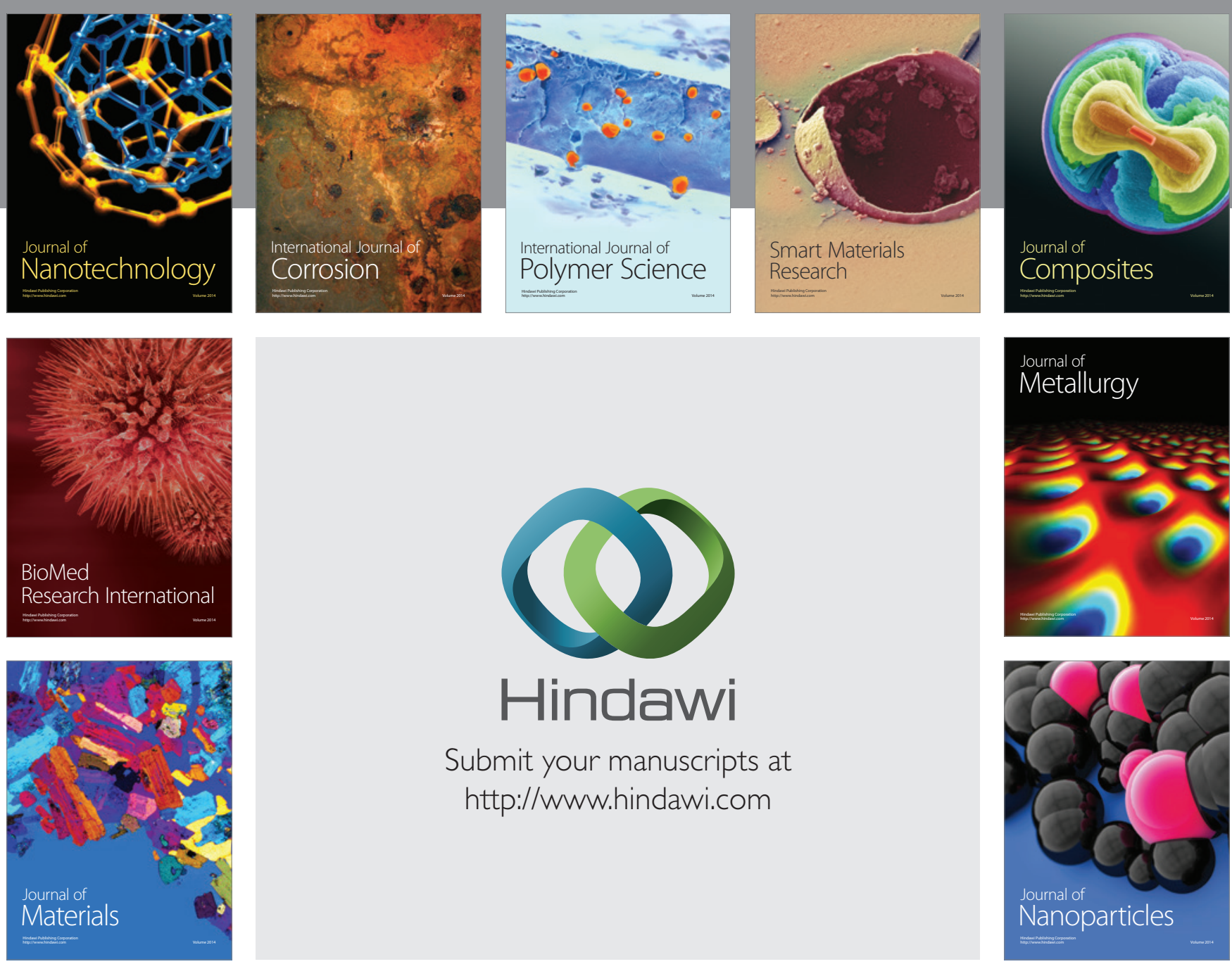

Submit your manuscripts at http://www.hindawi.com
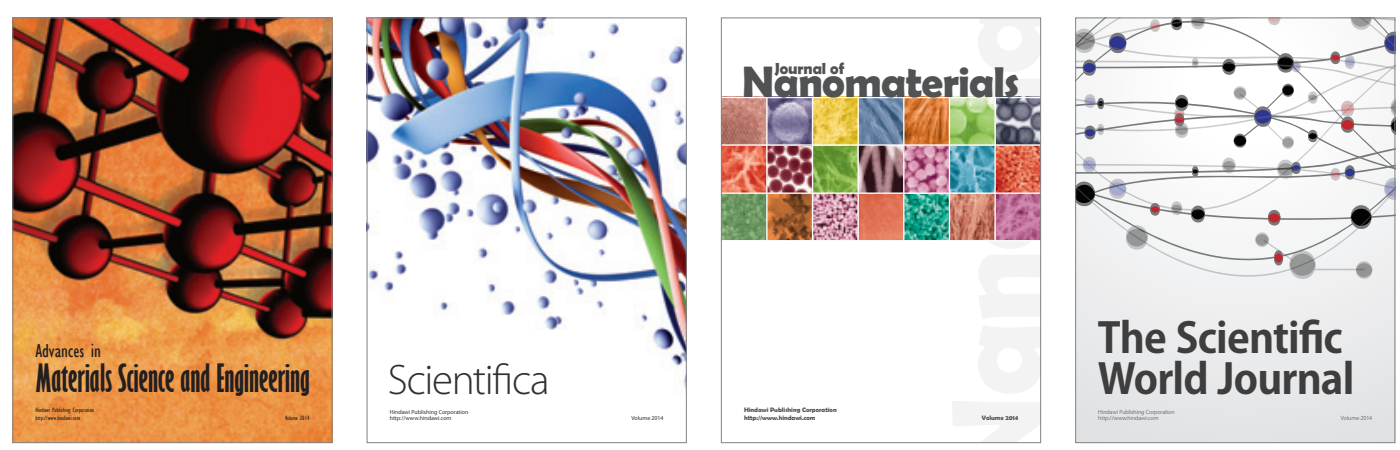

\section{The Scientific World Journal}
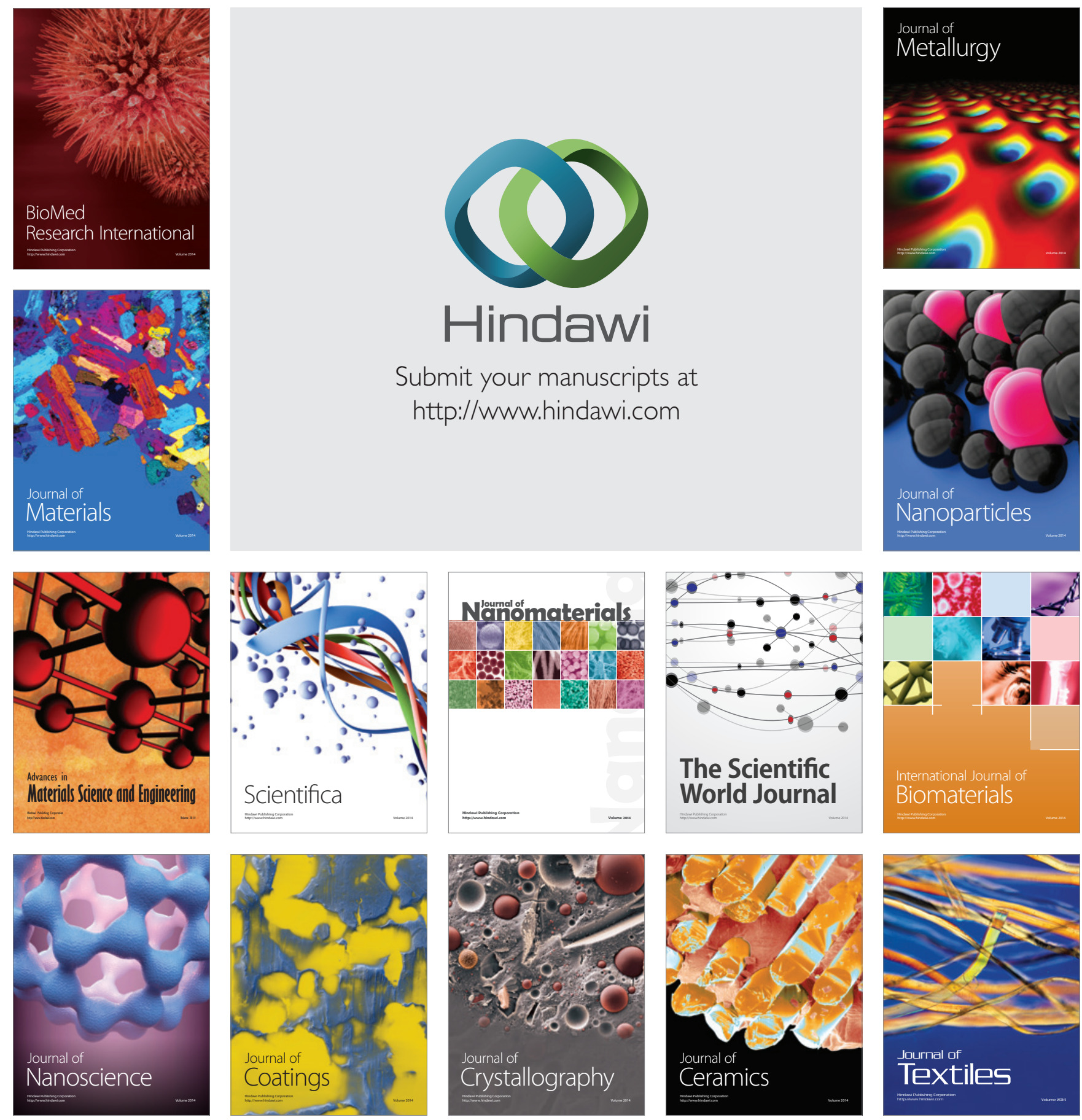